\title{
Stay local or go regional? Urban form effects on vehicle use at different spatial scales: A theoretical concept and its application to the San Francisco Bay Area
}

\author{
Dimitris Milakis \\ Delft University of Technology \\ and University of California, \\ Berkeley \\ d.milakis@tudelft.nl
}

\author{
Robert Cervero \\ University of California, Berkeley \\ robertc@berkeley.edu
}

\author{
Bert van Wee \\ Delft University of Technology \\ G.P.vanWee@tudelft.nl
}

\begin{abstract}
This paper explores the respective roles of local and regional characteristics of urban form on vehicle travel. We hypothesize that the effects of urban form on vehicle use at the local and regional levels are complementary, and we introduce the concept of local and regional action spaces, which are defined based on the accessibility of alternative means of transport within an acceptable travel time, to test this hypothesis. Multilevel and ordered logit models are developed for the San Francisco Bay Area to estimate the effects of urban form and socioeconomic characteristics on vehicle kilometers traveled (VKT) and vehicle trip frequency (for work, shopping, and social/recreational purposes). We find that the two urban scale characteristics exert complementary effects on VKT. However, because people in the San Francisco Bay Area display significantly lower VKT in the local than in the regional action space, we conclude that regional-scale interventions would contribute more to the policy objective of VKT reduction, although local-scale design policies might also help reach this policy goal. Intersection density (for the local action space models) and regional jobs accessibility (for the regional action space models) demonstrated the strongest and most significant relationships with VKT. The built environment did not appear to significantly affect vehicle trip frequency, which is likely due to the uniformly high levels of vehicle use in both the local and regional action spaces in the area.
\end{abstract}

\author{
Article history: \\ Received: November 28, 2013 \\ Received in revised form: October \\ 3, 2014 \\ Accepted: October 7, 2014 \\ Available online: June 19, 2015 \\ Data availability: \\ Metropolitan Transportation \\ Commission (MTC), San Francisco \\ Bay Area: \\ http://www.mtc.ca.gov/maps_and_ \\ data/datamart/survey/ and Associa- \\ tion of Bay Area \\ Governments (ABAG): \\ http://www.bayareacensus.ca.gov/
}

1

Introduction

Over the last two decades, several studies have focused on the relationship between the physical characteristics of urban form and travel choices with the objective of supporting more sustainable urban and transportation policies. Research in this area falls along a spectrum from total focus on the local spatial scale to total focus on the regional spatial scale, with most studies falling somewhere in between. The studies that focus more on the local scale argue that intervention in urban micro-scale characteristics - such as road network structure and form, bicycle and pedestrian infrastructures, urban furniture, neighborhood-level density and local accessibility — can reduce private vehicle use and increase the use of alternative means of

Copyright 2015 Dimitris Milakis, Robert Cervero, and Bert van Wee

http://dx.doi.org/10.5198/jtlu.2015.557

ISSN: 1938-7849 | Licensed under the Creative Commons Attribution - Noncommercial License 3.0

The Journal of Transport and Land Use is the official journal of the World Society for Transport and Land Use (WSTLUR) and is published and sponsored by the University of Minnesota Center for Transportation Studies.

This paper is also published with sponsorship from WSTLUR and the Institutes of Transportation Studies at University of California, Davis, and University of California, Berkeley. 
transport (Friedman, Gordon, and Peers 1992, Cervero and Groham 1995, Cervero and Kockelman 1997, McNally and Kulkarni 1997, Crane and Crepeau 1998, Krizek 2003, Frank and Engelke 2005, Khattak and Rodriguez 2005, Cao, Mokhtarian, and Handy 2009). The studies that focus more on the regional scale contend that increasing the overall density of the city, reducing the distances from dominant centers, mixing land uses, and avoiding large-scale mono-functional areas are associated with more sustainable travel choices (Banister 1992, 1997, 1999, Breheny 1995, Curtis 1995, Naess, Gunnar Roe, and Larsen 1995, Naess and Sandberg 1996, Naess 2003, Stead 2001, Schwanen, Dieleman, and Dijst 2001, 2004, Schwanen 2002, Milakis, Vlastos, and Barbopoulos 2008).

However, interventions at the local scale seem to have limited potential to affect a significant share of private vehicle usage because the destinations for many trips are beyond the travelers' neighborhoods (Cervero 1995). According to the 2001 US National Household Travel Survey, approximately 40 percent of vehicle kilometers traveled (VKT) are for trips that are 30 miles (48 kilometers) or longer (Boarnet 2011). These trips are expected to increase in the future given labor specialization, the growth of two- or multiple-income families, and the diffusion of jobs and other activities. By contrast, regional-scale interventions, which might create the conditions for reducing the length and volume of vehicle trips, are frequently accompanied by side effects (such as congestion and local environmental degradation) that affect cities with limited infrastructure for alternative modes of transport, in particular (Frank and Engelke, 2005, Melia, Parkhurst, and Barton 2011).

This study aims to explore the respective roles of the local and regional characteristics of urban form on vehicle travel. To this end, the first version of a theoretical concept is developed and applied in a simplified manner to the case of the San Francisco Bay Area. This paper is organized as follows. Section 2 explores whether and how the spatial scale issue has been addressed in the land use-transportation literature. Section 3 presents our research hypothesis and the theoretical concept that accompanies it. In section 4, we describe our methods, and in section 5, we present our results. Finally, in section 6, we draw some conclusions and offer suggestions for future research in this area.

\section{Background}

The discussion regarding spatial scales in the land-use transport literature has mainly focused on the level of spatial aggregation of urban form metrics and the potential effects of decisions regarding these metrics on the validity and transferability of research results (see Handy 1996, van Wee 2002, Chatman 2008, Zhang and Kukadia 2005, Hong, Shen, and Zhang 2013 for a detailed discussion of the modifiable areal unit problem). Relatively few studies have investigated the complementary effects of different urban spatial-scale characteristics on travel. All the relevant studies have used cross-sectional and (in most cases) disaggregated data in multivariate models of travel behavior.

To the best of our knowledge, Handy (1992) was the first to systematically explore the effects of urban form on travel behavior at the local and regional scales, although several researchers had earlier recognized that people's travel choices may be affected by the position of their neighborhood with respect to the larger settlement pattern (see, e.g., Kulash 1990, Friedman, Gordon and Peers 1992, Lerner-Lam et al. 1992). Handy analyzed non-work walking and car trips to local and regional centers for 400 residents in four Bay Area neighborhoods and compared their travel choices based on the accessibility profiles of each area. The study found that those areas with high local accessibility (regardless of their regional accessibility) were characterized by higher percentages of walking trips but did not conclude whether there had been a shift from car trips to walking trips. In their study of Seattle, McCormack, Rutherford, and Wilkinson (2001) showed that only 20 percent of trip destinations were within a kilometer of the mixed-use neighborhoods they studied. These authors subsequently argued that different levels of regional accessibility would have a significant impact on residents' travel patterns. Several other studies have shown the important role of regional factors, including distance from the core of the city (Miller and Ibrahim 1998, Zegras 2010, Naess 2011 in Toronto, Santiago, and Copenhagen, respectively), distance from other secondary employment 
centers (Miller and Ibrahim 1998, Naess 2011), and employment density at higher geographic levels in southern California (Boarnet and Sarmiento 1998).

A number of studies have found that local-scale variables better explain travel behavior than regionallevel characteristics. For instance, in their study of five neighborhoods in the Bay Area, Kitamura, Mokhtarian, and Laidet (1997) showed that the micro-scale parameters (distance to nearest bus stop, rail station, grocery store, gas station, park) offered greater explanatory power in all models (number and share of trips for various modes) compared with macro-scale descriptors (access to Bay Area Rapid Transit, mixed land use, high density). More recently, Manaugh and El-Geneidy (2012) found in Montreal that local accessibility is a more important factor than regional accessibility and that the effects of both local and regional accessibility measures significantly varied with household characteristics. In their study of six metropolitan areas in the United States, Nasri and Zhang (2012) employed most of the same variables for both regional and local spatial scales (population density, employment density, average block size, and average entropy) and demonstrated that neighborhood-level characteristics affect VKT more than metropolitan-level features. Moreover, in their study of Bogota, Cervero et al. (2009) found that only street density and connectivity were significant predictors of utilitarian walking and cycling. However, the low variation in the mixed-use and density levels in Bogota's neighborhoods might explain why these variables did not appear as significant in the models.

Finally, few studies have directly addressed the importance of complementarity among different spatial scales. For example, in his study of Boston and Hong Kong, Zhang (2004) showed that the combined effect of micro- and meso-scale features (e.g., densification and increased connectivity) on driving probability was similar to the effect of driving cost, whereas individual elasticities of land-use measures were comparatively low. Additionally, in their study of Wallonia, Belgium, Dujardin et al. (2012) found that regional-scale interventions might lead to energy savings for commuting of up to 21 percent (up to 23 percent for local interventions), suggesting more multi-scalar, context-specific policy interventions in urban and rural areas to achieve better energy consumption rates for commuting. Finally, in the Netherlands, Meurs and Haaijer (2001) concluded that the effects of individual spatial characteristics from different spatial scales are relatively limited, whereas a combinatorial scenario of increased density and mixed land use together with low local and regional car accessibility would shift a significant number of trips from the car to alternative modes of transportation.

3

\section{Research hypothesis and theoretical constructs}

The main hypothesis of this research is that urban micro- and macro-scale characteristics exert complementary effects on vehicle trip frequency and VKT. Micro-scale characteristics measure the built environment at the local spatial level with respect to density (residential, employment), diversity (mix of land uses, jobs-housing balance), and design (intersection density, intersection type, street density, presence and width of sidewalks, bicycle lanes, block size and form, parking provision, street trees, urban furniture). Macro-scale characteristics measure the built environment at the regional spatial level regarding density (residential, employment), diversity (e.g., mix of land uses), and destination accessibility (distance to the central business district, distance to secondary centers, accessibility to jobs). We assume that the complementarity between the effects of the two urban scales results from the existence of two action spaces (Hägerstrand 1970, Dijst 1999) that individuals consider when they make travel decisions: (a) the local (multimodal) action space, which is defined as the area that the typical walking, bicycle, and public transport user can reach within an acceptable travel time for a one-way trip, and (b) the regional (monoor oligo-modal) action space, which complements the local action space and is dominated by automobiles (see Figure 1). Thus, our "complementarity" hypothesis can be viewed as two sub-hypotheses: 
H1: Vehicle trip frequency and VKT (for work, shopping, and social/recreational purposes) within the local action space are mainly affected by urban micro-scale characteristics and less affected by urban macro-scale characteristics.

H2: Vehicle trip frequency and VKT (for work, shopping, and social/recreational purposes) outside of the local action space are mainly affected by urban macro-scale characteristics and less affected by urban micro-scale characteristics.

The theoretical link for the first sub-hypothesis is that within the local action space, a well-designed local environment would increase the cost of vehicle use (in terms of both time and money) and also make alternative modes of transport more attractive. Therefore, we might expect a modal shift toward walking, cycling, and public transport, which would likely lead to fewer VKT. We would also expect a direct decrease in VKT because of the shorter vehicle trip distances in a local environment characterized by high intersection density and consequently shorter blocks. Conversely, changing the regional built environment (e.g., creating new secondary centers) is not expected to significantly affect vehicle use and VKT for trips that are currently made locally because the change would likely involve additional transportation costs.

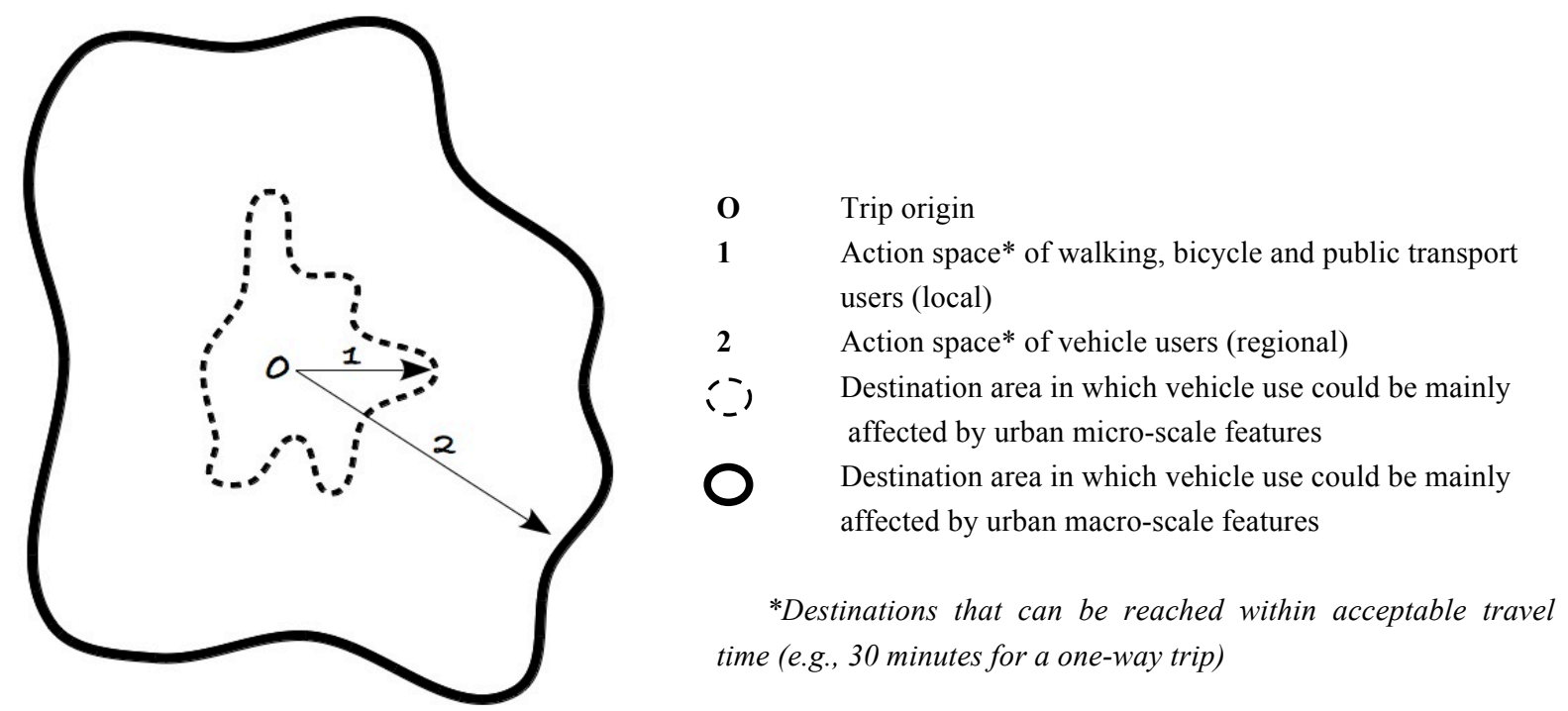

Figure 1: Graphical representation of the research hypothesis

The theoretical link for the second sub-hypothesis is that outside of the local action space, a more compact polycentric urban environment would directly reduce VKT because of shorter trip distances (assuming a balanced and matched jobs-housing relationship in the centers) and increase the use of alternative modes of transport (assuming a transit-networked region). Conversely, changing the local environment is not expected to significantly affect vehicle trip frequency and VKT for regional trips simply because there is no alternative to automobiles for reaching these destinations (within acceptable travel times).

The underlying assumption in our research hypothesis is that people consider an acceptable travel time for each trip they want to make, which is a factor that is incorporated into their travel decision processes (trip time budget, or TRTB). The TRTB concept draws from the concept of the travel time budget (TTB) (see Mokhtarian and Chen 2004 for a detailed review) but makes no assumption about the amount of total daily travel time. Instead, TRTB focuses on one-way trips, assuming that a city's average trip time reflects the average acceptable travel time in one direction that individuals use (among other considerations) to make travel decisions. The TRTB concept embodies the idea of ideal commute time and also that travel has a positive (intrinsic) utility (Hupkes 1982, Mokhtarian and Salomon 2001, Redmond and Mokhtarian 2001, Jain and Lyons 2008). However, it adds another critical point in trip timelines: the acceptable travel time threshold. This threshold means that individuals do in fact have an ideal time that 
they would like to spend on travel but that they tolerate spending more time until they find that the overall benefits (derived and intrinsic) gained from the trip have decreased. Derived utility is that utility associated with the activity at the trip destination, and any other travel-related utility (or disutility) is considered intrinsic.

We can divide the timeline of a one-way trip into three main periods regarding total utility changes: growth, tolerance, and decay (see Figure 2). The growth period occurs until the traveler reaches his or her ideal travel time. Both derived and intrinsic utility and, consequently, total utility increase because the disutility of time has no significant effect yet. The growth period is when people enjoy travel and, simultaneously, the potential derived utility from the number and quality of destinations that can be reached over the time steadily increases. The tolerance period is between the ideal and acceptable travel times. As a traveler surpasses his or her ideal travel time, the joy of travel decreases, and boredom (Gatersleben and Uzzell 2007), monotony, fatigue, and satiation are likely to set in (Hupkes 1982). Therefore, intrinsic utility begins to decrease until it reaches zero. By contrast, derived utility continues to increase, but at a lower rate, which might mean that the traveler realizes that the additional (marginal) derived benefits of traveling longer decrease (law of diminishing returns, see Rietveld and van Woudenberg 2003, Maat, van Wee, and Stead 2005) or that less time remains for other activities (which is likely with higher utility, see Hupkes 1982, Dijst 1999). The total utility slightly increases because of these two divergent partial utility processes until it reaches its maximum level, when the increase rate of derived utility equals the decrease rate of intrinsic utility. Therefore, the traveler is expected to tolerate longer-than-ideal travel times until he or she reaches the acceptable time threshold. The decay period begins at this point. The decrease rate for intrinsic utility becomes higher, and the derived utility continues to increase, but not strongly. Consecutively, total utility decreases- perhaps because people cannot tolerate more traveling-because excess travel is contrary to their instincts (Marchetti 1994) or because of the substantial amount of time and energy spent away from home (see Young and Morris 1981, Novaco, Stokols, and Milanesi 1990, Evans and Wener 2006, Novaco and Gonzalez 2009 for a review of commuting stress, and Hägerstrand 1985 for the principle of return).

It should be noted that travel time is only one potential factor involved in travel and destination decisions. For example, a destination may be within an acceptable travel time but not selected because it may not satisfy other criteria for the decision maker (e.g., type of job or shopping mall). Moreover, given the high variability of intrinsic and derived utilities, acceptable travel time is expected to vary across individuals and for a specific individual on different occasions (e.g., trip purpose, time of day, traveling companions, etc.). There are also preliminary indications that the acceptable travel time threshold does not strongly vary between different modes and between car and public transportation users, in particular. In his analysis of Canadian workers' perceptions of their daily commutes, Turcotte (2006) showed that the addition of the time factor (commute duration) in his model eliminated the difference between drivers and public transport users in their attitudes toward commuting. Moreover, both Hupkes (1982) and Redmond and Mokhtarian (2001) suggested that an ideal commute time is not affected by transport mode, and Young and Morris (1981) identified a similar pattern regarding levels of satisfaction with commute times for both transit and car users. 


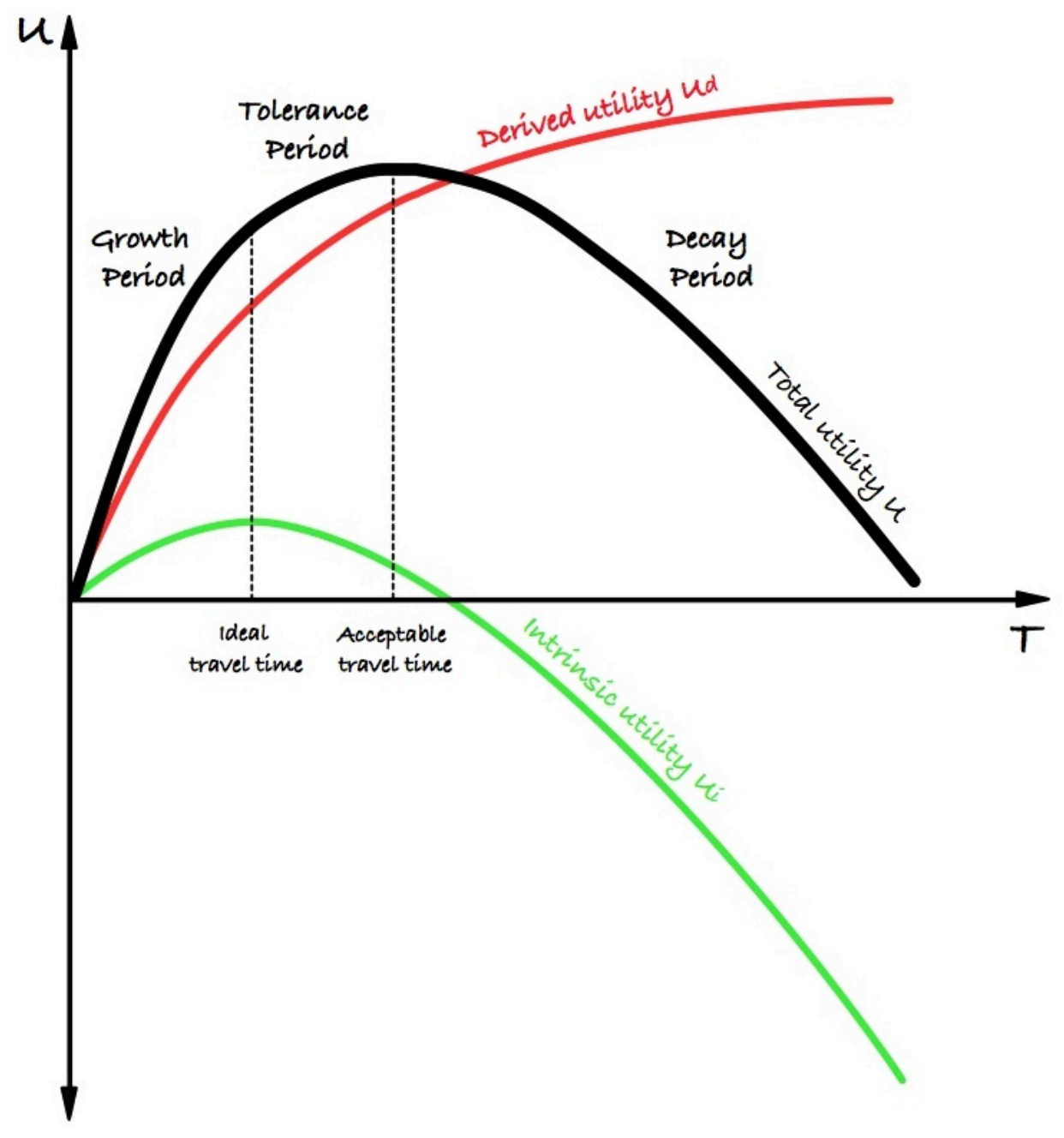

Figure 2: The three periods in the timeline of a trip (X-axis: Time - T, Y-axis: Utility - U)

4

Methods

\subsection{The urban and transport context}

The San Francisco Bay Area is the second-largest metropolitan area in California and a major economic center, comprising nine counties and 101 cities with a total population of 7,151,000 (2010) that is projected to reach 9,299,000 by 2040 (ABAG-MTC 2013). It has a polycentric urban form (Cervero and Wu 1997 ) in which the city of San Francisco is the most important center, followed by San Jose and Oakland. Together, these centers account for 33.5 percent of the jobs and 30.9 percent of the housing stock in the Bay Area (ABAG-MTC 2013). The area has both historically and more recently experienced significant suburban housing and employment growth (Scott 1985, Walker 2001), which have contributed to in- 
creased commute distances and associated transport externalities (Cervero and Wu 1998) and led to losses of agricultural lands and natural resources (Walker 2007).

Approximately 10.5 percent of work trips in the Bay Area are made by public transportation (MTC 2008), which is nearly double the rate in most US cities (Buehler 2008). Moreover, vehicle use for work trips is slightly lower ( 85.1 percent) than in other US cities (typically exceeding 88 percent). Walking and cycling rates to work (3.3 percent and 1.2 percent, respectively) do not differ from other US cities' averages, although both indicators are higher if other trip purposes are taken into account as well (10.3 percent and 1.8 percent, respectively). Roughly half of trips are less than 5 kilometers, and the average trip length is 11.2 kilometers (median trip length: 4.8 kilometers). Vehicle availability is 1.78 vehicles/household (MTC 2008).

\subsection{Estimation of the local and regional action spaces}

The network radius of local action space $\left(\mathrm{R}_{\text {(local) }}\right)$ was calculated for three trip purposes (work, shopping, and social/recreational) using equations 1 and 2 and is presented in Table 1, along with the average trip duration (acceptable travel time based on the TRTB hypothesis) and the mean speeds of travel modes. The results show that $\mathrm{R}_{\text {(local) }}$ for work trips was the largest of all three and was roughly twice that of so$\mathrm{cial} /$ recreational trips and 1.3 times the value for shopping trips.

$$
R_{(\text {local }) j}=A T T_{j} \times \max \left\{\bar{V}_{\mathrm{wj}}, \bar{V}_{\mathrm{cj}}, \bar{V}_{\mathrm{ptj}}\right\}
$$

where $R_{\text {(local) }}$ is the network radius for trip purpose $j, A T T$ is the acceptablelaverage trip time, $\bar{V}_{w}$ is the mean speed of walking, $\bar{V}_{c}$ is the mean speed of cyclists, and $\bar{V}_{p t}$ is the mean speed of public transport.

$$
\bar{V}_{\mathrm{ij}}=1 / t_{i j} \sum_{t=1}^{n} T L_{i j} / T T_{i j}
$$

where $\bar{V}_{i j}$ is the mean speed of mode $i$ and trip purpose $j, T L$ is the trip length calculated as the network distance between the geocoded origin and destination of the trip, TT is the reported trip time, and $t$ is the number of trips.

Table 1: The network radius of local action space per trip purpose as a product of the average trip duration and the highest mean speed among the three alternative means of transport

\begin{tabular}{|l|c|c|c|c|c|c|}
\hline Trip purpose & $\begin{array}{c}\text { Average trip duration } \\
\text { (min.) }\end{array}$ & \multicolumn{4}{|c|}{ Average speed (km/h) } & \multirow{2}{*}{$\mathrm{R}_{\text {(local) }}(\mathrm{km})$} \\
\cline { 3 - 6 } & & Vehicle & Walking & Cycling & $\begin{array}{c}\text { Public } \\
\text { transport }\end{array}$ & \\
\hline Work & 38.1 & 34.68 & 5.13 & 13.81 & 10.74 & 8.77 \\
\hline Shopping & 33.9 & 23.64 & 4.18 & 9.70 & 11.82 & 6.68 \\
\hline Social/Recreational & 28.3 & 27.64 & 4.20 & 9.66 & 9.53 & 4.56 \\
\hline
\end{tabular}

\subsection{Built environment, socioeconomic and travel variables}

Two measures of individuals' travel behavior were employed in this study: VKT and vehicle trip frequency. Both were calculated over the course of the two Bay Area Travel Survey (BATS2000) days for three trip purposes (work, shopping, and social/recreational) (Table 2). VKT per person was positively skewed and therefore was log-transformed. 
The explanatory variables of the study were divided into three groups (socioeconomic, urban microscale, and urban macro-scale) (see Table 3). The network distance of household to central business district (CBD) and distance to the nearest secondary center, along with urban activity (sum of net population and employment density), jobs-housing balance and regional-scale jobs accessibility were used as major indicators for urban macro-scale characteristics. Intersection density, block size, urban activity, jobs accessibility, and local-scale jobs-housing balance were used as major indicators for urban micro-scale characteristics. Household income, size, and number of vehicles, along with age and gender, comprised the socioeconomic variables.

We chose to use major indicators instead of the typically large number of built environment and socioeconomic variables for two reasons: 1) it is highly likely that urban features are highly correlated, particularly within each spatial scale (see Kitamura, Mokhtarian, and Laidet 1997, Brownstone 2008, Cervero et al. 2009); and 2) the aim of this research is not to investigate the detailed effects of each and every urban feature but to explore the broader relationships of urban form and travel behavior among different urban scales. The selection of major indicators was based on two extensive review studies (Ewing and Cervero 2001, 2010). Additionally, according to Dill (2004), block size (area) and intersection density are among the typical measures of network connectivity. Moreover, Appleyard (2013) argues that average parcel size could serve as a proxy for the aesthetic aspects of the built environment (human scale, image, enclosure, transparency, complexity, and tidiness). Other researchers have also recently sought to offer a reduced set of metrics to quantify neighborhood form, including street density and connectivity (Song, Popkin, and Gordon-Larsen 2013). Distance to secondary centers has not been used frequently in US research but has been employed in relevant studies in Europe (Naess 2011, 2012).

Data on socioeconomic (and travel) variables were derived from the BATS2000, the most recent regional household survey in the nine-county Bay Area. BATS2000 collected information on all in-home and out-of-home activities over a two-day period (sampling rate: 0.61 percent; 15,064 households; response rate: 13.7 percent) (MTC 2004). Respondents were initially contacted by phone, mailed travel diaries, and contacted again by phone to gather their travel information. Census and spatial data from MTC and ABAG were used to calculate the built environment variables. All data were processed in ArcGIS 10.1.

All micro-scale features were calculated at a two-kilometer radius from the household location to ensure that the attributes of both the immediate surroundings and the wider local area were captured. Regional jobs accessibility was measured as the number of jobs within 22 kilometers of a household location. The isochronic threshold derived from the TRTB assumption. Regional jobs-housing balance and urban activity were calculated for the same radius from the household location. CBD (San Francisco) and secondary centers (San Jose, Oakland, and Berkeley) were identified based on the Metropolitan Transit Commission's area type designation. Network distances between household locations and CBD/secondary centers were estimated with the help of an ArcGIS network analyst.

Table 2: The outcome variables of the study

\begin{tabular}{|c|c|c|c|c|c|c|}
\hline & \multicolumn{2}{|c|}{ Work } & \multicolumn{2}{|c|}{ Shop } & \multicolumn{2}{|c|}{ Social/Recreational } \\
\hline & \multicolumn{6}{|c|}{ Action Space } \\
\hline & Local & Regional & Local & Regional & Local & Regional \\
\hline \# of vehicle trips/ & $2.49^{a}$ & 2.43 & 2.13 & 1.67 & 1.95 & 1.88 \\
\hline person/two days & $(1.42)^{b}$ & (1.14) & $(1.48)$ & $(0.98)$ & $(1.12)$ & $(1.04)$ \\
\hline \multirow{2}{*}{ VKT/person/two days } & 11.29 & 67.59 & 6.50 & 29.67 & 4.81 & 32.11 \\
\hline & $(8.70)$ & $(57.53)$ & $(5.30)$ & (26.37) & $(3.42)$ & $(33.79)$ \\
\hline
\end{tabular}


Table 3: The explanatory variables of the study

\begin{tabular}{|c|c|c|c|}
\hline Socioeconomic variables & Description & Mean & StDev \\
\hline Household income & $\begin{array}{l}\text { Gross income of all persons living in household } \\
1 \text { below } \$ 10,000 \\
2 \$ 10,000 \text { to below } \$ 15,000 \\
3 \$ 15,000 \text { to below } \$ 20,000 \\
4 \$ 20,000 \text { to below } \$ 25,000 \\
5 \$ 25,000 \text { to below } \$ 30,000 \\
6 \$ 30,000 \text { to below } \$ 35,000 \\
7 \$ 35,000 \text { to below } \$ 40,000 \\
8 \$ 40,000 \text { to below } \$ 45,000 \\
9 \$ 45,000 \text { to below } \$ 50,000 \\
10 \$ 50,000 \text { to below } \$ 60,000 \\
11 \$ 60,000 \text { to below } \$ 75,000 \\
12 \$ 75,000 \text { to below } \$ 100,000 \\
13 \$ 100,000 \text { to below } \$ 125,000 \\
14 \$ 125,000 \text { to below } \$ 150,000 \\
15 \$ 150,000 \text { or more }\end{array}$ & $12.00^{\mathrm{a}}$ & $3.00^{\mathrm{b}}$ \\
\hline Household size & Number of persons in household & 2.96 & 1.38 \\
\hline Household vehicles & $\begin{array}{l}\text { Number of vehicles (not including bikes, scooters, and motorcycles) } \\
\text { in household }\end{array}$ & 2.18 & 0.91 \\
\hline Age (quadratic transformation) & Age of individual (years) & 40.9 & 18.2 \\
\hline Gender & 0:male, 1:female & 0.53 & 0.50 \\
\hline \multicolumn{4}{|l|}{ Urban micro-scale variables } \\
\hline Intersection density & $\begin{array}{l}\text { Number of intersections within } \mathrm{R}=2 \mathrm{~km} \text { from household location } \\
\text { (Intersections } / \mathrm{km}^{2} \text { ) }\end{array}$ & 28.28 & 15.28 \\
\hline Block size & Average block size within $\mathrm{R}=2 \mathrm{~km}$ from household location (ha) & 13.00 & 15.59 \\
\hline Urban activity_L(ocal) & $\begin{array}{l}\text { Sum of net population and employment density within } \mathrm{R}=2 \mathrm{~km} \\
\text { from household location (Persons+Jobs/ha of developed area) }\end{array}$ & 50.37 & 60.14 \\
\hline Jobs accessibility_L(ocal) & Number of jobs within $\mathrm{R}=2 \mathrm{~km}$ from household location & 12,276 & 20,468 \\
\hline Jobs-Housing balance_L(ocal) & $\begin{array}{l}\text { Ratio of number of jobs to employed residents within } \mathrm{R}=2 \mathrm{~km} \text { from } \\
\text { household location }\end{array}$ & 0.87 & 0.80 \\
\hline \multicolumn{4}{|l|}{ Urban macro-scale variables } \\
\hline Distance to CBD & $\begin{array}{l}\text { Network distance between household location and the centroid of } \\
\text { the San Francisco CBD }(\mathrm{km})\end{array}$ & 56.89 & 26.86 \\
\hline Distance to nearest secondary center & $\begin{array}{l}\text { Network distance between household location and the centroid of } \\
\text { the nearest secondary center (San Jose, Oakland, or Berkeley) }(\mathrm{km})\end{array}$ & 34.18 & 24.10 \\
\hline Urban activity_R(egional) & $\begin{array}{l}\text { Sum of net population and employment density within } \mathrm{R}=22 \mathrm{~km} \\
\text { from household location (Persons+Jobs/ha of developed area) }\end{array}$ & 41.30 & 20.06 \\
\hline Jobs accessibility_R(egional) & Number of jobs within $\mathrm{R}=22 \mathrm{~km}$ from household location & 670,375 & 400,914 \\
\hline Jobs-Housing balance_R(egional) & $\begin{array}{l}\text { Ratio of number of jobs to employed residents within } \mathrm{R}=22 \mathrm{~km} \\
\text { from household location }\end{array}$ & 1.12 & 0.24 \\
\hline (a) Median, ( $\left.{ }^{\mathrm{b}}\right)$ Interquartile range & & & \\
\hline
\end{tabular}




\subsection{Model specifications}

Given the nested structure of the data (person, household, neighborhood, region), H1 and H2 for VKT were tested using a system of two multilevel models (MLMs). MLMs can include both fixed effect parameters that are related to continuous or categorical predictors and random effects to account for the random variation of dependent variables at different levels of data (West, Welch, and Galecki 2007). Intra-class correlation (ICC) was used to measure between-group variance for the outcome variable. The MLM can be represented as follows:

$$
y=X \beta+Z u+\varepsilon
$$

where $y$ is a vector of observations, mean $\mathrm{E}(\mathrm{y})=\mathrm{X} \beta, \beta$ is a vector of fixed effects, $\mathrm{u}$ is a vector of random effects with mean $\mathrm{E}(\mathrm{u})=0$ and variance-covariance matrix $\operatorname{var}(\mathrm{u})=\mathrm{G}, \varepsilon$ is a vector of random error terms with mean $\mathrm{E}(\varepsilon)=0$ and variance $\operatorname{var}(\varepsilon)=\mathrm{R}$, and $\mathrm{X}$ and $\mathrm{Z}$ are matrices of regressors relating the observations y to $\beta$ and $u$.

The frequency of vehicle trips at a disaggregate level is a discrete ordered choice and was therefore represented by an ordered logit model (ORL) ${ }^{1}$. ORL is derived by defining a latent variable $\mathrm{z}$ to be used as the basis for modeling the ordinal ranking of data-in this case, vehicle trip frequency. The number of vehicle trips is then specified as a linear function for each observation (Washington, Karlaftis, and Mannering 2011):

$$
z_{n}=\beta X_{n}+\varepsilon
$$

where $\mathrm{X}$ is a vector of variables that determine the discrete ordering for observation $\mathrm{n}$ (in our case, socioeconomic and urban micro- and macro-scale features), $\beta$ is a vector of estimable parameters, and $\varepsilon$ is a residual. Using this equation, observed ordinal data y for each observation are defined as follows:

$$
\begin{aligned}
& y=1, \quad \text { if } z \leq \mu_{0} \\
& y=2, \quad \text { if } \mu_{0}<z \leq \mu_{1} \\
& y=3, \\
& \text { if } \mu_{1}<z \leq \mu_{2} \\
& \quad y=\cdots \\
& y=I, \quad \text { if } z \geq \mu_{I-2}
\end{aligned}
$$

where $\mu$ represent estimable parameters (referred to as thresholds) that define y (which corresponds to integer ordering), and $\mathrm{I}$ is the highest integer ordered response.

The analysis for each trip purpose, in both the local and regional action spaces, was conducted in hierarchical steps for both VKT and vehicle trip frequency. First, base models were developed, and only the group of socioeconomic variables was used. Next, the urban micro- and macro-scale descriptors were added to the base model, one at a time. The next step involved comparing the model fit improvement that each group of built environment variables offered to the base model using likelihood ratio tests (West, Welch, and Galecki 2007). A final model that included all significant explanatory variables (identified through sequential elimination by excluding non-significant variables) was developed, allowing for a deep-

\footnotetext{
${ }^{1}$ ICC for vehicle trip frequency showed very low values $(<0.03$ in most models); therefore, the multilevel model specification was rejected.
} 
er investigation of specific relationships with VKT and vehicle trip frequency. VKT elasticities were computed for each individual person and averaged over the sample. All MLM and ORL analyses were performed using the R statistical software (the "nlme" package Pinheiro et al. 2013, and the "ordinal" package Christensen 2012, respectively).

\section{$5 \quad$ Results}

\subsection{VKT models}

We estimated two MLM models (i.e., local and regional action space models) for each of the three trip purposes considered in this study (work, shopping, and social/recreational). Goodness-of-fit changes are presented in Table 4.

Table 4: Changes in the goodness-of-fit of the four-level (person, household, neighborhood-traffic analysis zone (TAZ), regioncounty) hierarchical linear models for VKT from the addition of the micro- and macro-built environment descriptors to the base model (socioeconomic descriptors only). Likelihood ratios of the base models show their significance in comparison with the intercept-only models.

\begin{tabular}{|c|c|c|c|c|c|c|}
\hline \multirow{2}{*}{ VKT models } & \multicolumn{3}{|c|}{ Local action space } & \multicolumn{3}{|c|}{ Regional action space } \\
\hline & $\mathrm{X}^{2}$ & p-value & df & $X^{2}$ & p-value & $\mathrm{df}$ \\
\hline \multicolumn{7}{|l|}{ Work trips } \\
\hline Base $(s / o)^{a}$ & 79.06 & 0.000 & 5 & 239.81 & 0.000 & 5 \\
\hline+ Micro $^{b}$ & 34.81 & 0.000 & 5 & 8.70 & 0.122 & 5 \\
\hline+ Macro $^{c}$ & 12.83 & 0.025 & 5 & 154.11 & 0.000 & 5 \\
\hline+ Micro and Macro & 53.12 & 0.000 & 10 & 174.63 & 0.000 & 10 \\
\hline \multicolumn{7}{|l|}{ Shopping trips } \\
\hline Base (s/o) & 155.54 & 0.000 & 5 & 16.05 & 0.007 & 5 \\
\hline +Micro & 52.67 & 0.000 & 5 & 9.70 & 0.084 & 5 \\
\hline +Macro & 10.17 & 0.071 & 5 & 56.34 & 0.000 & 5 \\
\hline +Micro and Macro & 64.19 & 0.000 & 10 & 63.66 & 0.000 & 10 \\
\hline \multicolumn{7}{|c|}{ Social/Recreational trips } \\
\hline Base (s/o) & 18.55 & 0.002 & 5 & 38.49 & 0.000 & 5 \\
\hline +Micro & 13.95 & 0.016 & 5 & 40.43 & 0.000 & 5 \\
\hline +Macro & 14.72 & 0.011 & 5 & 48.34 & 0.000 & 5 \\
\hline +Micro and Macro & 22.39 & 0.013 & 10 & 67.68 & 0.000 & 10 \\
\hline \multicolumn{7}{|c|}{ a S/O: socioeconomic descriptors (age, gender, household income, household size, and number of household vehicles) } \\
\hline \multicolumn{7}{|c|}{${ }^{b}$ Micro: micro-scale descriptors (intersection density, block size, urban activity_L, jobs accessibility_L, and jobs-housing balance_L) } \\
\hline \multirow{2}{*}{\multicolumn{7}{|c|}{$\begin{array}{l}\text { 'Macro: macro-scale descriptors (distance to } C B D \text {, distance to nearest secondary center, urban activity_R, jobs accessibility_R, and jobs-housing } \\
\text { balance_R) }\end{array}$}} \\
\hline & & & & & & \\
\hline \multicolumn{7}{|c|}{ L: local-level indicator $(r=2 \mathrm{~km})$ and $R$ : regional-level indicator $(r=22 \mathrm{~km})$} \\
\hline
\end{tabular}


The built environment variables (both micro- and macro-scale) significantly improved the base models for all trip purposes. For example, in the case of work trips, the addition of micro- and macro-scale descriptors significantly improved both the local $\left(x^{2}=53.12, \mathrm{p}=0.000\right)$ and regional action space models $\left(x^{2}\right.$ $=174.63, \mathrm{p}=0.000)$. The micro-scale descriptors appeared to play a more important role in explaining VKT variance in the local action space model, whereas the macro-scale descriptors better explained VKT in the regional action space model for both work and shopping trips. For example, in the case of work trips, the addition of micro-scale descriptors significantly improved the local action space model fit $\left(x^{2}=\right.$ $34.81, \mathrm{p}=0.000)$, whereas the macro-scale variables led to only marginal improvement $\left(x^{2}=12.83, \mathrm{p}=\right.$ $0.025)$. Conversely, in the regional action space model, micro-scale variables did not add to the explanatory power of the base model $\left(x^{2}=8.70, \mathrm{p}=0.122\right)$, but macro-scale variables significantly improved it $\left(x^{2}=\right.$ $154.11, \mathrm{p}=0.000)$. In the case of social/recreational trips, micro- and macro-scale descriptors offered similar levels of improvement for both the local and regional action space models.

The next set of results addresses the final models for each trip purpose (see Tables 5 through 7). Specifically, for work trips, intersection density showed the strongest influence on VKT among all built environment variables $(\beta=-0.099, \mathrm{p}=0.000)$ in the local action space model (see Table 5). A 10 percent improvement in an area's connectivity seemed related to a 0.72 percent VKT reduction. By contrast, regional jobs accessibility showed the strongest effect on VKT in the regional action space model $(\beta=-$ $0.116, \mathrm{p}=0.000)$. According to the elasticity estimate, a 10 percent increase in jobs accessibility at the regional level was associated with a VKT reduction of 0.67 percent. Moreover, a 10 percent increase in the jobs-housing balance (i.e., 0.1 more jobs per employed resident) was associated with a 1.26 percent reduction in total VKT. Shopping trip models presented similar patterns of micro- and macro-scale features' effects on VKT (see Table 6). In the local action space model, intersection density showed the strongest relationship with VKT $(\beta=-0.098, \mathrm{p}=0.000)$, whereas jobs accessibility appeared to be the most important variable in the regional action space model $(\beta=-0.121, \mathrm{p}=0.000)$. Consistent with the first part of the analysis, the final models for social/recreational trips did not provide a clear indication of the relative strengths of the micro- and macro-scale features' effects on VKT (see Table 7). In the local action space model, intersection density and distance to CBD exerted similar influences on VKT $(\beta=-0.043, \mathrm{p}=$ 0.010 and $\beta=0.039, \mathrm{p}=0.020$, respectively $)$, and their elasticity estimates were also similar $(-0.027$ and 0.026 , respectively). In the regional action space model, regional jobs accessibility seemed to exert the strongest negative influence on VKT $(\beta=-0.103, \mathrm{p}=0.000)$, although block size also acted as a significant predictor of VKT $(\beta=0.056, \mathrm{p}=0.000)$.

Finally, with respect to socioeconomic characteristics, older travelers had more VKT for shopping and social/recreational purposes in the local action space $(\beta=0.116, \mathrm{p}=0.000$ and $\beta=0.048, \mathrm{p}=0.000$, respectively) but not for work trips. Men seemed to generate more VKT for work in both the local and regional action spaces $(\beta=-0.089, \mathrm{p}=0.000$ and $\beta=-0.142, \mathrm{p}=0.000$, respectively) and for social/recreational purposes in the regional action space $(\beta=-0.019, \mathrm{p}=0.000)$, and women seemed to generate more VKT for shopping in the local action space $(\beta=0.047 \cdot \mathrm{p}=0.000)$. More household vehicles were associated with more VKT for social/recreational purposes in the regional action space $(\beta=$ 0.044, $\mathrm{p}=0.004)$, whereas higher income was associated with more VKT for shopping in both the local and regional action spaces ( $\beta=0.034, \mathrm{p}=0.006$ and $\beta=0.033, \mathrm{p}=0.025$, respectively). 
Table 5: The final MLM models for predicting VKT generated by work trips

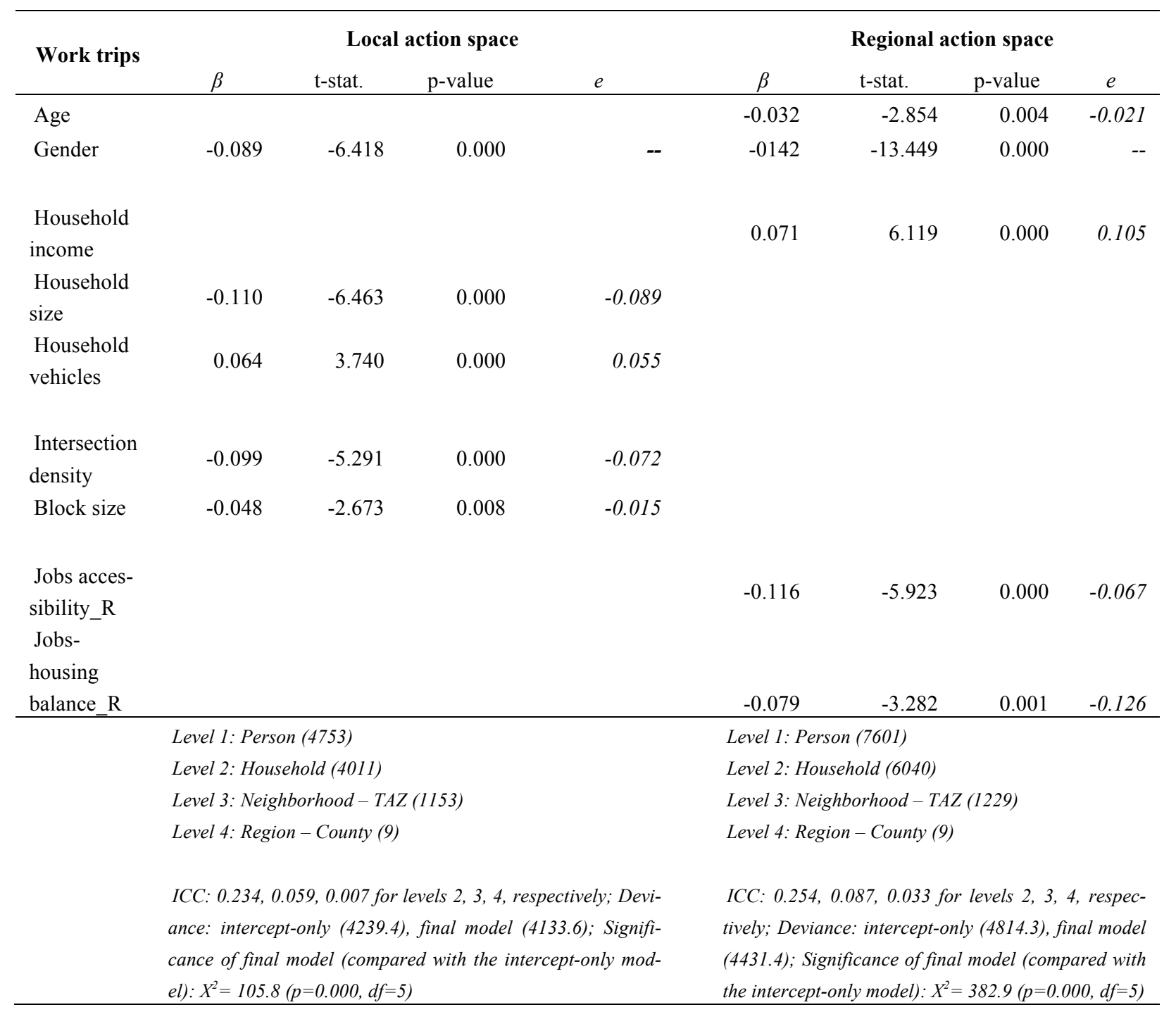


Table 6: The final MLM models for predicting VKT generated by shopping trips

\begin{tabular}{|c|c|c|c|c|c|c|c|c|}
\hline \multirow{2}{*}{ Shopping trips } & \multicolumn{4}{|c|}{ Local action space } & \multicolumn{4}{|c|}{ Regional action space } \\
\hline & $\beta$ & t-stat. & $\mathrm{p}$-value & $e$ & $\beta$ & t-stat. & p-value & $e$ \\
\hline Age & 0.116 & 9.444 & 0.000 & 0.054 & & & & \\
\hline Gender & 0.047 & 4.992 & 0.000 & -- & & & & \\
\hline Household income & 0.034 & 2.758 & 0.006 & 0.043 & 0.033 & 2.238 & 0.025 & 0.041 \\
\hline Household size & 0.102 & 7.390 & 0.000 & 0.078 & & & & \\
\hline Intersection density & -0.098 & -7.197 & 0.000 & -0.067 & & & & \\
\hline \multirow[t]{6}{*}{ Jobs accessibility_R } & & & & & -0.121 & -8.213 & 0.000 & -0.065 \\
\hline & \multicolumn{4}{|c|}{ Level 1: Person (8730) } & \multicolumn{4}{|c|}{ Level 1: Person (5655) } \\
\hline & \multicolumn{4}{|c|}{ Level 2: Household (5924) } & \multicolumn{4}{|c|}{ Level 2: Household (3951) } \\
\hline & \multicolumn{4}{|c|}{ Level 3: Neighborhood - TAZ (1221) } & \multicolumn{4}{|c|}{ Level 3: Neighborhood - TAZ (1128) } \\
\hline & \multicolumn{4}{|c|}{ Level 4: Region - County (9) } & \multicolumn{4}{|c|}{ Level 4: Region - County (9) } \\
\hline & \multicolumn{4}{|c|}{$\begin{array}{l}\text { ICC: } 0.391,0.060,0.004 \text { for levels } 2,3,4 \text {, re- } \\
\text { spectively; Deviance: intercept-only (6268.5), final } \\
\text { model (6064.2); Significance of final model (com- } \\
\text { pared with the intercept-only model): } X^{2}=204.3 \\
(p=0.000, d f=5)\end{array}$} & \multicolumn{4}{|c|}{$\begin{array}{l}\text { ICC: } 0.578,0.076,0.011 \text { for levels 2, 3, 4, re- } \\
\text { spectively; Deviance: intercept-only (2615.8), final } \\
\text { model (2557.6); Significance of final model (com- } \\
\text { pared with the intercept-only model): } X^{2}=58.2 \\
(p=0.000, d f=2)\end{array}$} \\
\hline
\end{tabular}


Table 7: The final MLM models for predicting VKT generated by social/recreational trips

\begin{tabular}{|c|c|c|c|c|c|c|c|c|}
\hline \multirow{2}{*}{$\begin{array}{l}\text { Social/Recreational } \\
\text { trips }\end{array}$} & \multicolumn{4}{|c|}{ Local action space } & \multicolumn{4}{|c|}{ Regional action space } \\
\hline & $\beta$ & t-stat. & $\mathrm{p}$-value & $e$ & $\beta$ & t-stat. & p-value & $e$ \\
\hline Age & 0.048 & 3.624 & 0.000 & 0.017 & & & & \\
\hline Gender & & & & & -0.019 & -2.271 & 0.023 & -- \\
\hline Household size & & & & & -0.089 & -5.536 & 0.000 & -0.074 \\
\hline Household vehicles & & & & & 0.044 & 2.879 & 0.004 & 0.040 \\
\hline Intersection density & -0.043 & -2.586 & 0.010 & -0.027 & & & & \\
\hline Block size & & & & & 0.056 & 3.608 & 0.000 & 0.018 \\
\hline Distance to CBD & 0.039 & 2.326 & 0.020 & 0.026 & & & & \\
\hline \multirow[t]{6}{*}{ Jobs accessibility_R } & & & & & -0.103 & -4.764 & 0.000 & -0.067 \\
\hline & \multicolumn{4}{|c|}{ Level 1: Person (6048) } & \multicolumn{4}{|c|}{ Level 1: Person (7815) } \\
\hline & \multicolumn{4}{|c|}{ Level 2: Household (3811) } & \multicolumn{4}{|c|}{ Level 2: Household (4898) } \\
\hline & \multicolumn{4}{|c|}{ Level 3: Neighborhood - TAZ (1106) } & \multicolumn{4}{|c|}{ Level 3: Neighborhood - TAZ (1179) } \\
\hline & \multicolumn{4}{|c|}{ Level 4: Region - County (9) } & \multicolumn{4}{|c|}{ Level 4: Region - County (9) } \\
\hline & \multicolumn{4}{|c|}{$\begin{array}{l}\text { ICC: } 0.541,0.025,0.003 \text { for levels } 2,3,4 \text {, respec- } \\
\text { tively; Deviance: intercept-only (2796.6), final } \\
\text { model (2768.7); Significance of final model (com- } \\
\text { pared with the intercept-only model): } X^{2}=27.9 \\
(p=0.000, d f=3)\end{array}$} & \multicolumn{4}{|c|}{$\begin{array}{l}\text { ICC: } 0.625,0.021,0.006 \text { for levels } 2,3,4 \text {, respec- } \\
\text { tively; Deviance: intercept-only (5511.3), final } \\
\text { model (5424.3); Significance of final model (com- } \\
\text { pared with the intercept-only model): } X^{2}=87.0 \\
(p=0.000, d f=5)\end{array}$} \\
\hline
\end{tabular}

\subsection{Vehicle trips models}

We estimated two ORL models (i.e., local and regional action space models) for each of the three trip purposes considered in this study (work, shopping, and social/recreation). Goodness-of-fit changes are presented in Table 8.

Contrary to the VKT models, adding the built environment variables (both micro- and macro-scale) did not substantially improve the vehicle trip frequency models. For example, for shopping trips, adding the built environment descriptors offered only marginal improvement in both the local and regional action space models $\left(x^{2}=25.98, \mathrm{p}=0.004\right.$ and $x^{2}=36.37, \mathrm{p}=0.000$, respectively). No specific pattern was identified regarding the effects of micro- and macro-scale descriptors for any of the three trip purposes. For example, in the case of work trips, macro-scale descriptors seemed to improve both the local and regional action space models' fits more than the micro-scale variables $\left(x^{2}=44.54, \mathrm{p}=0.000, x^{2}=31.48, \mathrm{p}=\right.$ 0.000 , respectively). 
Table 8: Changes in the goodness-of-fit of the ordinal logistic regression models for vehicle trip frequency from the addition of micro and macro built environment groups of descriptors to the base model (socioeconomic descriptors only). Likelihood ratios of the base models show their significance in comparison with the intercept-only models.

\begin{tabular}{|c|c|c|c|c|c|c|}
\hline \multirow{2}{*}{ Vehicle trip models } & \multicolumn{3}{|c|}{ Local action space } & \multicolumn{3}{|c|}{ Regional action space } \\
\hline & $\mathrm{X}^{2}$ & $\mathrm{p}$-value & $\mathrm{df}$ & $\mathrm{X}^{2}$ & $\mathrm{p}$-value & $\mathrm{df}$ \\
\hline \multicolumn{7}{|l|}{ Work trips } \\
\hline Base $(s / o)^{a}$ & 47.69 & 0.000 & 5 & 107.44 & 0.000 & 5 \\
\hline+ Micro $^{\mathrm{b}}$ & 31.60 & 0.000 & 5 & 3.23 & 0.665 & 5 \\
\hline+ Macro $^{c}$ & 44.54 & 0.000 & 5 & 31.48 & 0.000 & 5 \\
\hline +Micro and Macro & 61.00 & 0.000 & 10 & 51.39 & 0.000 & 10 \\
\hline \multicolumn{7}{|l|}{ Shopping trips } \\
\hline Base (s/o) & 187.35 & 0.000 & 5 & 90.21 & 0.000 & 5 \\
\hline+ Micro & 15.75 & 0.008 & 5 & 29.22 & 0.000 & 5 \\
\hline +Macro & 9.22 & 0.101 & 5 & 14.93 & 0.011 & 5 \\
\hline +Micro and Macro & 25.98 & 0.004 & 10 & 36.37 & 0.000 & 10 \\
\hline \multicolumn{7}{|l|}{$\begin{array}{l}\text { Social/Recreational } \\
\text { trips }\end{array}$} \\
\hline Base (s/o) & 40.71 & 0.000 & 5 & 30.20 & 0.000 & 5 \\
\hline +Micro & 17.44 & 0.004 & 5 & 33.35 & 0.000 & 5 \\
\hline+ Macro & 10.06 & 0.074 & 5 & 7.14 & 0.210 & 5 \\
\hline +Micro and Macro & 27.72 & 0.002 & 10 & 49.95 & 0.000 & 10 \\
\hline \multicolumn{7}{|c|}{$\begin{array}{l}\text { 'Micro: micro-scale descriptors (intersection density, block size, urban activity_L, jobs accessibility_L, and jobs housing balance_ } L \text { ) } \\
\text { 'Macro: macro-scale descriptors (distance to CBD, distance to nearest secondary center, urban activity_R, jobs accessibility_R, and jobs-housing balance_R) } \\
\text { L: local-level indicator }(r=2 \mathrm{~km}), R \text { : regional_level indicator }(r=22 \mathrm{~km})\end{array}$} \\
\hline
\end{tabular}

Moreover, in all final models (see Tables 9 through 11), socioeconomic variables appeared to influence vehicle trip frequency more than any micro- or macro-scale descriptors. Specifically, for work trips, the number of household vehicles showed the strongest positive effect on vehicle trip frequency in both the local and regional action space models (see Table 9). People in households with more vehicles were 16.2 percent (in the local action space) and 14.4 percent (in the regional action space) more likely to use private vehicles for work trips relative to those living in households with fewer vehicles. Household size also seemed to have a significant negative effect on vehicle use for work trips in both the local and regional action spaces (odds ratio $-\mathrm{OR}=0.912$; $\mathrm{OR}=0.943$, respectively). Moreover, higher household income appeared to slightly decrease the odds of using a private vehicle for work trips in comparison with people in lower-income households in both the local and regional action spaces $(\mathrm{OR}=0.967$; $\mathrm{OR}=0.983$, respectively). Women tended to use private vehicles for work trips less frequently than men, particularly for farther destinations $(\mathrm{OR}=0.835$, local action space; $\mathrm{OR}=0.696$, regional action space). Regarding the built environment variables, only distance to CBD seemed to have a slightly positive effect on vehicle trip frequency, which indicates that people living farther from a CBD are more likely ( 0.4 percent to 0.6 percent) to use their vehicles more frequently than are those who live closer to the CBD. With respect to shopping trips, two variables - household size and gender-appeared to be the most important determinants of vehicle trip frequency (see Table 10). However, in contrast to the relationship with work trips, household size showed a positive association with vehicle use: Those in larger households were 17.2 percent (in the 
regional action space) to 21.2 percent (in the local action space) more likely to make more vehicle trips for shopping purposes compared with those in smaller households. Moreover, women tended to use their vehicles more frequently than men for shopping purposes in local markets ( $\mathrm{OR}=1.238$, local action space). Finally, for social/recreational trips, household size appeared to be the single most important variable affecting vehicle trip frequency (see Table 11). Specifically, residents of large households were 6.9 percent (in the regional action space) to 11.3 percent (in the local action space) more likely to use private vehicles more frequently for social/recreational purposes in comparison with those in smaller households. 
Table 9: The final ORL models for predicting work trip frequency by private vehicle

\begin{tabular}{|c|c|c|c|c|c|c|c|c|c|c|}
\hline \multirow{2}{*}{ Work trips } & \multicolumn{5}{|c|}{ Local action space $(\mathrm{N}=\mathbf{4 7 5 3})$} & \multicolumn{5}{|c|}{ Regional action space $(\mathrm{N}=7601)$} \\
\hline & Coefficient & t-stat. & p-value & Odds Ratio & OR $95 \% C I$ & Coefficient & t-stat. & p-value & Odds Ratio & OR $95 \% C I$ \\
\hline \multicolumn{11}{|l|}{$\begin{array}{l}\text { Thresholds } \\
\text { (trips) }\end{array}$} \\
\hline (1) & -1.036 & $\begin{array}{c}- \\
8.399\end{array}$ & 0.000 & 0.355 & $0.279-0.452$ & -1.207 & -10.123 & 0.000 & 0.299 & $0.237-0.378$ \\
\hline$(2)$ & 0.338 & 2.756 & 0.006 & 1.402 & $1.102-1.782$ & 0.271 & 2.286 & 0.022 & 1.311 & $1.039-1.653$ \\
\hline (3) & 0.983 & 7.974 & 0.000 & 2.673 & $2.099-3.403$ & 1.099 & 9.235 & 0.000 & 3.002 & $2.377-3.790$ \\
\hline Age & & & & & & $0.54 \mathrm{E}-04$ & -2.520 & 0.012 & 1.000 & $1.000-1.000$ \\
\hline Gender & -0.180 & $\begin{array}{c}- \\
3.414\end{array}$ & 0.001 & 0.835 & $0.753-0.926$ & -0.362 & -8.567 & 0.000 & 0.696 & $0.641-0.756$ \\
\hline $\begin{array}{l}\text { Household in- } \\
\text { come }\end{array}$ & -0.033 & $\begin{array}{c}- \\
3.533\end{array}$ & 0.000 & 0.967 & 0.949-0.985 & -0.017 & -2.004 & 0.045 & 0.983 & $0.968-1.000$ \\
\hline Household size & -0.092 & $\begin{array}{c}- \\
4.009\end{array}$ & 0.000 & 0.912 & $0.872-0.954$ & -0.058 & -3.126 & 0.002 & 0.943 & $0.909-0.978$ \\
\hline $\begin{array}{l}\text { Household ve- } \\
\text { hicles }\end{array}$ & 0.150 & 4.535 & 0.000 & 1.162 & $1.089-1.239$ & 0.134 & 5.121 & 0.000 & 1.144 & $1.087-1.204$ \\
\hline \multirow[t]{2}{*}{$\begin{array}{l}\text { Distance to } \\
\text { CBD }\end{array}$} & 0.006 & 5.760 & 0.000 & 1.006 & $1.004-1.008$ & 0.004 & 5.405 & 0.000 & 1.004 & $1.003-1.006$ \\
\hline & \multicolumn{5}{|c|}{$\begin{array}{l}\text { Deviance: intercept-only model (12784.3), final model (12703.3) } \\
\text { Significance of final model (compared with the intercept-only model): } X^{2}= \\
81.00(p=0.000, d f=5)\end{array}$} & \multicolumn{5}{|c|}{$\begin{array}{l}\text { Deviance: intercept-only (20682.5), final model }(20545.8) \\
\text { Significance of final model (compared with the intercept-only model): } X^{2}= \\
136.7(p=0.000, d f=6)\end{array}$} \\
\hline
\end{tabular}


Table 10: The final ORL models for predicting shopping trip frequency by private vehicle

\begin{tabular}{|c|c|c|c|c|c|c|c|c|c|c|}
\hline \multirow{2}{*}{$\begin{array}{l}\text { Shopping } \\
\text { trips }\end{array}$} & \multicolumn{5}{|c|}{ Local action space $(\mathrm{N}=\mathbf{8 7 3 0})$} & \multicolumn{5}{|c|}{ Regional action space $(\mathrm{N}=\mathbf{5 6 5 5})$} \\
\hline & Coefficient & t-stat. & p-value & Odds Ratio & OR $95 \% C I$ & Coefficient & $t$-stat. & p-value & Odds Ratio & OR $95 \% C I$ \\
\hline \multicolumn{11}{|l|}{ Thresholds (trips) } \\
\hline (1) & 0.609 & 6.491 & 0.000 & 1.839 & $1.530-2.210$ & 0.846 & 5.945 & 0.000 & 2.329 & $1.763-3.078$ \\
\hline (2) & 2.112 & 21.910 & 0.000 & 8.268 & $6.844-9.988$ & 2.648 & 18.037 & 0.000 & 14.118 & $10.589-18.824$ \\
\hline (3) & 2.792 & 28.277 & 0.000 & 16.308 & 13.439-19.789 & 3.501 & 22.924 & 0.000 & 33.144 & $24.571-44.709$ \\
\hline Age & $1.2 \mathrm{E}-04$ & 8.986 & 0.000 & 1.000 & $1.000-1.000$ & $1.2 \mathrm{E}-04$ & 6.582 & 0.000 & 1.000 & $1.000-1.000$ \\
\hline Gender & 0.214 & 5.297 & 0.000 & 1.238 & $1.144-1.340$ & & & & & \\
\hline Household income & & & & & & -0.026 & -2.851 & 0.004 & 0.974 & $0.957-0.992$ \\
\hline Household size & 0.192 & 11.671 & 0.000 & 1.212 & $1.174-1.252$ & 0.159 & 7.456 & 0.000 & 1.172 & $1.124-1.222$ \\
\hline Household vehicles & -0.010 & -2.751 & 0.006 & 0.990 & $0.983-0.997$ & & & & & \\
\hline Intersection density & 0.005 & 4.012 & 0.000 & 1.006 & $1.003-1.008$ & & & & & \\
\hline Block size & & & & & & 0.006 & 4.143 & 0.000 & 1.006 & $1.003-1.009$ \\
\hline Distance to CBD & & & & & & 0.002 & 2.062 & 0.039 & 1.002 & $1.000-1.004$ \\
\hline \multirow[t]{2}{*}{ Urban activity_R } & -0.002 & $\begin{array}{r}- \\
2.396\end{array}$ & $\begin{array}{l}0.01 \\
7\end{array}$ & 0.998 & $0.995-1.000$ & & & & & \\
\hline & \multicolumn{5}{|c|}{$\begin{array}{l}\text { Deviance: intercept-only model (21765.3), final model (21565.6) } \\
\text { Significance of final model (compared with the intercept-only model): } X^{2}= \\
199.7(p=0.000, d f=6)\end{array}$} & \multicolumn{5}{|c|}{$\begin{array}{l}\text { Deviance: intercept-only (11717.9), final model (11608.2) } \\
\text { Significance of final model (compared with the intercept-only model): } X^{2}= \\
109.7(p=0.000, d f=5)\end{array}$} \\
\hline
\end{tabular}




\section{Conclusions}

Research on the effects of urban form on travel choices falls along a spectrum from total focus on the local spatial scale to total focus on the regional spatial scale, with most studies falling somewhere in between. Few studies fall right in the middle, with a focus on the relationship between local and regional influences. This study explored the respective roles of local and regional characteristics of urban form on vehicle travel. We hypothesized that the effects of urban form on vehicle use at the local and regional levels are complementary, and we formed the following sub-hypotheses:

H1. Vehicle trip frequency and VKT (for work, shopping, and social/recreational purposes) within the local action space are mainly affected by urban micro-scale characteristics and less affected by urban macro-scale characteristics.

H2. Vehicle trip frequency and VKT (for work, shopping, and social/recreational purposes) outside of the local action space are mainly affected by urban macro-scale characteristics and less affected by urban micro-scale characteristics.

MLM models for VKT and ORL models for vehicle trip frequency were developed to test these hypotheses.

Regarding VKT, built environment variables (both micro- and macro-scale) added significant explanatory power to all base models, which included only socioeconomic variables; this result is similar to the findings from other studies (see Kitamura, Mokhtarian, and Laidet 1997, Sun, Wilmot, and Kasturi 1998, Stead 2001, Limtanakool, Dijst, and Schwanen 2006, Chen and McKnight 2007, Milakis, Vlastos, and Barbopoulos 2008). The "complementarity" hypothesis seemed to be confirmed for VKT regarding both work and shopping trips. In other words, urban micro-scale descriptors were more important for explaining VKT in the local action space models, whereas macro-scale descriptors better explained VKT in the regional action space models. The hypothesis was not confirmed for so$\mathrm{cial} /$ recreational trips. Most likely, social/recreational trip destinations are more diffuse than they are concentrated in urban centers. Therefore, regional structure variables such as distance to CBD or to secondary centers do not likely capture their variance. Another explanation may be that the concept of acceptable travel time and consequently the logic of local and regional action spaces do not apply to these types of trip purposes. The "complementarity" hypothesis was also confirmed in the final models in which intersection density (for the local action space models) and regional jobs accessibility (for the regional action space models) showed the strongest and most significant relationships with VKT. Consistent with previous research, increased intersection density and-consequently-area connectivity (see Boarnet, Nesamani, and Smith 2004, Chapman and Frank 2004, Chatman 2008, Cervero et al. 2009) and increased regional jobs accessibility (see Miller and Ibrahim 1998, Sun, Wilmot, and Kasturi 1998, Kuzmyak, Baber, and Savory 2006, Cervero and Duncan 2006) are associated with lower VKT. Elasticity estimates for the first parameter in this study varied between -0.027 and -0.072 and between 0.065 and 0.067 for the second parameter. These values were lower than previous findings (see Ewing and Cervero $2010,0.12$ for intersection density and 0.20 for jobs accessibility by car), although studies with similar indicators and analysis units reported elasticity values that were closer to our results (e.g., Chapman and Frank 2004). Neither local nor regional urban activity (sum of population and employment density) appeared as a statistically significant factor for VKT, which is consistent with previous research in the San Francisco Bay Area (Kockelman 1997). 
However, which of the two scales contributes more to the potential decrease of VKT? To answer this question, we should consider that people in the Bay Area display significantly lower VKT (per person) in the local than in the regional action space, at a ratio of 1:6.0 for work trips, 1:4.6 for shopping trips and 1:6.7 for social/recreational trips (the respective ratios of total VKT in the local action space to total VKT in the regional action space are 1:9.6, 1:3.0 and 1:8.6). This lower VKT means that regional-scale interventions can contribute more to the policy target of VKT reduction, although local-scale design policies can also help reach this target in the framework of a synergistic and integrated approach. This result is consistent with previous studies that have found that regional urban form features matter more for VKT than local-level urban form characteristics (see Miller and Ibrahim 1998, Zegras 2010, Naess 2011).

Contrary to the results from the VKT model, built environment variables (both micro- and macroscale) did not appear to significantly affect vehicle trip frequency. Moreover, the "complementarity" hypothesis was not confirmed in the final models because no specific pattern was identified regarding the effects of micro- and macro-scale descriptors for any of the three trip purposes (work, shopping, and social/recreational). One possible explanation is the limited variation in vehicle trip frequency among the different areas of the city. According to our results, Bay Area residents tend to use their vehicles almost equally often for both short (within the local action space) and long (outside the local action space) trips. Consistent with our results, Handy (1992) found in her study on four Bay Area communities that, although higher local accessibility may induce more walking trips, these are frequently made in addition to-rather than in place of-driving trips. Consequently, the potential for VKT reduction comes mainly from reducing travel distances rather than by diverting some vehicle trips to alternative means of transportation. Extrapolating these thoughts into planning policy, a simultaneous intervention on the local and regional scales would likely not affect vehicle trip frequency in the Bay Area but would reduce VKT. However, if these policies were combined with a significant expansion of public transportation, bicycling, and pedestrian networks, then the potential for further VKT reduction might be greater because at least parts of vehicle trips might be diverted to more sustainable modes.

On a methodological level, this study has some strengths but also several limitations. The concept of local and regional action spaces along with the concept of acceptable travel time allowed us to delve deeper into the possible behavioral mechanisms behind the relative importance of local and regional urban form features for vehicle use. This study embodies the first version of those concepts, and their application to the San Francisco Bay Area involved several simplifications that must be taken into account. Future research can offer additional evidence with respect to both the validity of the theoretical concepts and the relative importance of local and regional urban form features for vehicle use. First, the validity of the acceptable travel time concept must be qualitatively and quantitatively explored. Moreover, we did not have data regarding the potential heterogeneity of acceptable travel times, and therefore, this heterogeneity was not incorporated into the estimations of the local and regional action spaces. We simplified the analysis by assuming that acceptable travel time is reflected at the aggregate level by the average trip time at the city level. Further research on the variability of acceptable travel time across individuals, trip motivations, mode of transport, time of day and other occasions would allow a (more) disaggregated estimation and a more realistic representation of the local and regional action spaces. High variability of acceptable travel time would also indicate a fuzzier distinction between local and regional action spaces on the aggregate level. Second, even if acceptable travel time is shown to be a valid theoretical concept, it is uncertain whether people make travel decisions by mentally forming local and regional action spaces. It is one thing to use action spaces as an analytical tool based on Hägerstrand's (1970) well-established theory, but it is another to assume that such a concept has the value of a behavioral decision rule. It is also uncertain which modes of transport are considered part of the local (multimodal) or the regional (mono or oligo-modal) action spaces. For example, it might be the case that someone's local action space comprises only bicycling and walking, whereas public transport and car are included in the regional action space. In this paper, we have assumed that bicycling, walking, and all public transport modes form the so-called local action space or the action space of the alternative modes of transport. An alternative ap- 
proach could be to incorporate only bicycling, walking, and local public transport in the local action space and leave regional public transport systems, such as the metro and the train, in the regional action space. Further research to explore the validity of the idea of action spaces as decision rules and experimentation with different modes of transport in local and regional action spaces might add to the robustness of the results. Third, although cross-effects between local and regional scales are also possible (i.e., regional characteristics might influence local trips and local characteristics might influence regional trips) — particularly for shopping trips— this study did not include such effects in its modeling approach because we focused our attention on the relative importance of the main effects (i.e., the effect of local characteristics on local trips and regional characteristics on regional trips). A more complete exploration of the effects of urban form on vehicle use at different scales should involve cross-effects as well. Handy (1992) suggested a qualitative approach for identifying this type of effect that would allow a deeper exploration of the motivations and potential trade-offs in travel choices. Fourth, the use of disaggregated data limited the MAUP possibility (Zhang and Kukadia 2005) in our study, but our cross-sectional analysis-in addition to the fact that people may self-select their home locations based on their travel preferences-did not enable us to make strong causal statements about the explored relationships. Finally, our case study, the San Francisco Bay Area, has certain unique characteristics; therefore, applying this methodology to more US metropolitan areas might help overcome generalizability issues.

\section{$7 \quad$ Acknowledgments}

This research was supported by a Marie Curie International Outgoing Fellowship within the Seventh European Community Framework Program. The first author would like to thank Susan Handy, University of California, Davis, for her comments on an earlier version of this paper; Shimon Israel, Metropolitan Transportation Commission, San Francisco Bay Area, and Fletcher Foti, University of California, Berkeley, for providing data on the San Francisco Bay Area; and John Bigham, University of California, Berkeley, for his assistance in processing the data in a GIS environment. The paper has also greatly benefited from the comments of three anonymous reviewers. 


\section{References}

Appleyard, B. 2013. Deconstructing the D-variables: New methods to measure the built environment for travel behavior research. Presented at the Transportation Research Board 92nd Annual Meeting, January 13-17, 2013. URL: http://trid.trb.org/view.aspx?id=1242994

Association of Bay Area Governments and Metropolitan Transportation Commission. 2013. Plan Bay Area. Strategy for a Sustainable Region (Draft). San Francisco, CA: ABAG-MTC. URL: http://onebayarea.org/pdf/Draft_Plan_Bay_Area_3-22-13.pdf

Banister, D. 1992. Energy use, transport and settlement patterns. In Sustainable Development and Urban Form, edited by M.J. Breheny, 160-181. London: Pion.

Banister, D. 1997. Reducing the need to travel. Environment and Planning B: Planning and Design 24(3): 437-449. http://dx.doi.org/10.1068/b240437

Banister, D. 1999. Planning more to travel less. Land use and transport. Town Planning Review 70(3): 313-338. URL: http://www.jstor.org/stable/40111776

Boarnet, M. G. 2011. A broader context for land use and travel behavior, and a research agenda. Journal of the American Planning Association 77(3): 197-213. http://dx.doi.org/10.1080/01944363.2011.593483

Boarnet, M. G., K. S. Nesamani, and S. Smith. 2004. Comparing the influence of land use on nonwork trip generation and vehicle distance traveled: An analysis using travel diary data. Presented at the Transportation Research Board 83rd Annual Meeting, January 11-15, 2004. URL: http://escholarship.org/uc/item/4xf6r519\#page-1

Boarnet, M. G., and S. Sarmiento. 1998. Can land-use policy really affect travel behavior? A study of the link between non-work travel and land-use characteristics. Urban Studies 35(7): 1155-1169. http://dx.doi.org/10.1080/0042098984538

Breheny, M. 1995. The compact city and transport energy consumption. Transactions of the Institute of British Geographers 20(1): 81-101. http://dx.doi.org/10.2307/622726

Brownstone, D. 2008. Key relationships between the built environment and VMT. Relationships among development patterns, vehicle miles traveled, and energy consumption, paper prepared for the Transportation Research Board panel. URL: http://onlinepubs.trb.org/Onlinepubs/sr/sr298brownstone.pdf

Buehler, R. 2008. Transport policies, travel behavior, and sustainability: A comparison of Germany and the US. PhD thesis, Rutgers. URL: http://rucore.libraries.rutgers.edu/rutgers-lib/24085/PDF/1/

Cao, X., P. L. Mokhtarian, and S. L. Handy. 2009. The relationship between the built environment and non-work travel: A case study of northern California. Transportation Research Part A: Policy and Practice 43(5): 548-559. http://dx.doi.org/10.1016/j.tra.2009.02.001

Cervero, R. 1995. Sustainable new towns. Stockholm's rail-served satellites. Cities 12(1): 41-51. http://dx.doi.org/10.1016/0264-2751(95)91864-C

Cervero, R., and M. Duncan. 2006. Which reduces vehicle travel more: Jobs-housing balance or retailhousing mixing? Journal of the American Planning Association 72(4): 475-490. http://dx.doi.org/10.1080/01944360608976767

Cervero, R., and R. Groham. 1995. Commuting in transit versus automobile neighborhoods. Journal of the American Planning Association 61(2): 210-225.

Cervero, R., and K. Kockelman. 1997. Travel demand and the 3Ds: Density, diversity, and design. Transportation Research Part D: Transport and Environment 2(3): 199-219. http://dx.doi.org/10.1016/S1361-9209(97)00009-6

Cervero, R., O. L. Sarmiento, E. Jacoby, L. F. Gomez, and A. Neiman. 2009. Influences of built environments on walking and cycling: Lessons from Bogotá. International Journal of Sustainable Transportation 3(4): 203-226. http://dx.doi.org/10.1080/15568310802178314

Cervero, R., and K. L. Wu. 1997. Polycentrism, commuting, and residential location in the San Francisco Bay Area. Environment and Planning A 29(5): 865-886. http://dx.doi.org/10.1068/a290865 
Cervero, R., and K. L. Wu. 1998. Sub-centring and commuting: Evidence from the San Francisco Bay Area, 1980-90. Urban Studies 35(7): 1059-1076. http://dx.doi.org/10.1080/0042098984484

Chapman, J., and L. Frank. 2004. Integrating travel behavior and urban form data to address transportation and air quality problems in Atlanta. Washington DC: US Department of Transportation. URL: http://atl.sites.olt.ubc.ca/files/2011/06/GDOT_final_report.pdf

Chatman, D. 2008. Deconstructing development density: Quality, quantity and price effects on household non-work travel. Transportation Research Part A: Policy and Practice, 42(7): 1008-1030. http://dx.doi.org/10.1016/j.tra.2008.02.003

Chen, C., and C. E. McKnight. 2007. Does the built environment make a difference? Additional evidence from the daily activity and travel behavior of homemakers living in New York City and suburbs. Journal of Transport Geography 15(5): 380-395. http://dx.doi.org/10.1016/j.jtrangeo.2006.11.010

Christensen, R. H. B. 2012. Ordinal: Regression Models for Ordinal Data R Package Version 2012.09-11. URL: http://www.cran.r-project.org/package=ordinal/.

Crane, R., and R. Crepeau. 1998. Does neighborhood design influence travel? A behavioral analysis of travel diary and GIS data. Transportation Research Part D: Transport and Environment 3(4): 225-238. http://dx.doi.org/10.1016/S1361-9209(98)00001-7

Curtis, C. 1995. Reducing the need to travel: Strategic housing location and travel behavior. In Reducing the Need to Travel: Some Thoughts on PPG13, edited by J.H. Earp, P. Headicar, D. Banister and C. Curtis. Oxford Planning Monographs 1(2), 29-47. Oxford: Oxford Brookes University, School of Planning.

Dijst, M. 1999. Action space as planning concept in spatial planning. Netherlands Journal of Housing and the Built Environment 14(2): 163-182. http://dx.doi.org/10.1007/BF02496820

Dill, J. 2004. Measuring network connectivity for bicycling and Walking. Presented at the Transportation Research Board 83rd Annual Meeting, January 11-15, 2004. URL: http://reconnectingamerica.org/assets/Uploads/TRB2004-001550.pdf

Dujardin, S., F. Pirart, F. Brévers, A. F. Marique, and J. Teller. 2012. Home-to-work commuting, urban form and potential energy savings: A local scale approach to regional statistics. Transportation Research Part A: Policy and Practice 46(7): 1054-1065. http://dx.doi.org/10.1016/j.tra.2012.04.010

Evans, G. W., and R. E. Wener. 2006. Rail commuting duration and passenger stress. Health Psychology 25(3): 408-412. http://dx.doi.org/10.1037/0278-6133.25.3.408.

Ewing, R., and R. Cervero. 2001. Travel and the built environment: A Synthesis. Transportation Research Record 1780: 87-114. http://dx.doi.org/10.3141/1780-10

Ewing, R., and R. Cervero. 2010. Travel and the built environment: A meta-analysis. Journal of the American Planning Association 76(3): 265-294. http://dx.doi.org/10.1080/01944361003766766

Frank, L. D., and P. Engelke 2005. Multiple impacts of the built environment on public health: Walkable places and the exposure to air pollution. International Regional Science Review 28(2): 193-216. http://dx.doi.org/10.1177/0160017604273853

Friedman B., P. Gordon, and J. Peers. 1992. The effect of neotraditional neighborhood design on travel characteristics. In Compendium of Technical Papers. District 6 Annual Meeting, 195-208. Institute of Transportation Engineers.

Gatersleben, B., and D. Uzzell. 2007. Affective appraisals of the daily commute: Comparing perceptions of drivers, cyclists, walkers, and users of public transport. Environment and Behavior 39(3): 416-431. http://dx.doi.org/10.1177/0013916506294032

Hägerstrand, T. 1970. What about people in regional science? Papers of the Regional Science Association 24: 7-21. http://dx.doi.org/10.1007/BF01936872

Hägerstrand, T. 1985. Time-geography: Focus on the corporeality of man, society, and environment. In The Science and Praxis of Complexity, 193-216. Tokyo: The United Nations University press.

Handy, S. 1992. Regional versus local accessibility: Neo-traditional development and its implications for non-work travel. Built Environment 18(4): 253-267. URL: http://www.jstor.org/stable/23288518 
Handy, S. 1996. Methodologies for exploring the link between urban form and travel behavior. Transportation Research Part D: Transport and Environment 1(2): 151-165. http://dx.doi.org/10.1016/S1361-9209(96)00010-7

Hong, J., Q. Shen, and L. Zhang. 2013. How do built-environment factors affect travel behavior? A spatial analysis at different geographic scales. Transportation 41(3): 419-440. http://dx.doi.org/10.1007/s11116-013-9462-9

Hupkes, G. 1982. The law of constant travel time and trip-rates. Futures 14(1): 38-46. http://dx.doi.org/10.1016/0016-3287(82)90070-2

Jain, J., and G. Lyons. 2008. The gift of travel time. Journal of Transport Geography 16(2): 81-89. http://dx.doi.org/10.1016/j.jtrangeo.2007.05.001

Khattak, A. J., and D. Rodriguez. 2005. Travel behavior in neo-traditional neighborhood developments: A case study in USA. Transportation Research Part A: Policy and Practice 39(6): 481-500. http://dx.doi.org/10.1016/j.tra.2005.02.009

Kitamura, R., P. L., Mokhtarian, and L. Laidet. 1997. A micro-analysis of land use and travel in five neighborhoods in the San Francisco Bay Area. Transportation 24(2): 125-158. http://dx.doi.org/10.1023/A:1017959825565

Kockelman, K. 1997. Travel behavior as function of accessibility, land use mixing and land use balance evidence from San Francisco Bay Area. Transportation Research Record 1607: 116-125. http://dx.doi.org/10.3141/1607-16

Krizek, K. J. 2003. Residential relocation and changes in urban travel: Does neighborhood-scale urban form matter? Journal of the American Planning Association 69(3): 265-281. http://dx.doi.org/10.1080/01944360308978019

Kulash, W. 1990. Traditional neighborhood development: Will the traffic work? Presented at the 11 th Annual Pedestrian Conference, Bellevue, WA, October 1990.

Kuzmyak, J. R., C. Baber, and D. Savory. 2006. Use of walk opportunities index to quantify local accessibility. Transportation Research Record, 1977: 145-153. http://dx.doi.org/10.3141/1977-19

Lerner-lam, E., S .P. Celniker, G. W. Halbert, C. Chellman, and S. Ryan. 1992. Neo-traditional neighborhood design and its implications for traffic engineering. ITE Journal (January): 17-25. URL: http://citeseerx.ist.psu.edu/viewdoc/download?doi=10.1.1.182.6240\&rep=rep1\&type=pdf

Limtanakool, N., M. Dijst, and T. Schwanen. 2006. The influence of socioeconomic characteristics, land use and travel time considerations on mode choice for medium- and longer-distance trips. Journal of Transport Geography 14(5): 327-341. http://dx.doi.org/10.1016/j.jtrangeo.2005.06.004

Maat, K., B. van Wee, and D. Stead. 2005. Land use and travel behavior: Expected effects from the perspective of utility theory and activity-based theories. Environment and Planning B: Planning and Design, 32(1): 33-46. http://dx.doi.org/10.1068/b31106

Manaugh, K., and A. El-Geneidy. 2012. What makes travel "local": Defining and understanding local travel behavior. Journal of Transport and Land Use 5(3): 15-27. http://dx.doi.org/10.5198/jtlu.v5i3.300

Marchetti, C. 1994. Anthropological invariants in travel behavior. Technological forecasting and social change 47(1): 75-88. http://dx.doi.org/10.1016/0040-1625(94)90041-8

McCormack, E., G. S. Rutherford, and M. G. Wilkinson. 2001. Travel impacts of mixed land use neighborhoods in Seattle, Washington. Transportation Research Record 1780: 25-32. http://dx.doi.org/10.3141/1780-04

McNally M. G., and A. Kulkarni. 1997. Assessment of influence of land use-transportation system on travel behavior. Transportation Research Record, 1607: 105-115. http://dx.doi.org/10.3141/1607-15

Melia, S., G. Parkhurst, and H. Barton. 2011. The paradox of intensification. Transport Policy, 18(1): 46-52. http://dx.doi.org/10.1016/j.tranpol.2010.05.007

Metropolitan Transportation Commission (MTC) 2004. San Francisco Bay Area Travel Survey 2000. Regional Travel Characteristics Report. Volume I. Oakland, CA: MTC. URL: ftp://ftp.abag.ca.gov/pub/mtc/planning/BATS/BATS2000/Travel_Characteristics/Vol_I.zip 
Metropolitan Transportation Commission (MTC) 2008. Change in Motion (Transportation 2035 Plan for the San Francisco Bay Area. Travel Forecasts Data Summary). San Francisco, CA: MTC. URL: http://www.mtc.ca.gov/planning/2035_plan/Supplementary/T2035-

Travel_Forecast_Data_Summary.pdf

Meurs, H., and P. Haaijer. 2001. Spatial structure and mobility. Transportation Research Part D: Transport and Environment 6(6): 429-446. http://dx.doi.org/10.1016/S1361-9209(01)00007-4

Milakis, D., T. Vlastos, and N. Barbopoulos. 2008. Relationships between urban form and travel behavior in Athens, Greece. A comparison with Western European and North American results. European Journal of Transport and infrastructure Research 8(3): 201-215. URL: http://stat.onestat.com/link.aspx?sid=228684\&linkid=37

Miller, E., and A. Ibrahim. 1998. Urban form and vehicular travel: some empirical findings. Transportation Research Record 1617: 18-27. http://dx.doi.org/10.3141/1617-03

Mokhtarian, P. L., and C. Chen. 2004. TTB or not TTB? That is the question: A review and analysis of the empirical literature on travel time (and money) budgets. Transportation Research Part A: Policy and Practice 38(9-10): 643-675. http://dx.doi.org/10.1016/j.tra.2003.12.004

Mokhtarian, P. L., and I. Salomon. 2001. How derived is the demand for travel? Some conceptual and measurement considerations. Transportation Research Part A: Policy and Practice 35(8): 695-719. http://dx.doi.org/10.1016/S0965-8564(00)00013-6

Naess, P. 2003. Urban structures and travel behavior. Experiences from empirical research in Norway and Denmark. European Journal of Transport and infrastructure Research 3(2): 155-178. URL: http://www.ejtir.tudelft.nl/issues/2003_02/pdf/2003_02_03.pdf

Naess, P. 2011. "New urbanism" or metropolitan-level centralization? A comparison of the influences of metropolitan-level and neighborhood-level urban form characteristics on travel behavior. Journal of Transport and Land Use 4(1): 25-44. http://dx.doi.org/10.5198/jtlu.v4i1.170

Naess, P. 2012. Urban form and travel behavior: Experience from a Nordic context. Journal of Transport and Land Use 5(2): 21-45. http://dx.doi.org/10.5198/jtlu.v5i2.314

Naess, P., P. Gunnar Roe, and S. Larsen. 1995. Traveling distances, modal split and transportation energy in thirty residential areas in Oslo. Journal of Environmental Planning and Management 38(3): 349370. http://dx.doi.org/10.1080/09640569512913

Naess, P., and S. L. Sandberg. 1996. Workplace location, modal split and energy use for commuting trips. Urban Studies 33(3): 557-580. http://dx.doi.org/10.1080/00420989650011915

Nasri, A., and L. Zhang. 2012. Impact of metropolitan-level built environment on travel behavior. Transportation Research Record 2323: 75-79. http://dx.doi.org/10.3141/2323-09

Novaco, R., and O. Gonzalez. 2009. Commuting and well-being. In Technology and Well-Being, edited by Y. Amichai-Hamburger, 174-205. New York: Cambridge University Press.

Novaco, R. W., D. Stokols, and L. Milanesi. 1990. Objective and subjective dimensions of travel impedance as determinants of commuting stress. American Journal of Community Psychology 18(2): 231257. http://dx.doi.org/10.1007/BF00931303

Pinheiro, J., D. Bates, S. DebRoy, D. Sarkar, and R Development Core Team. 2013. nlme: Linear and Nonlinear Mixed Effects Models. R package version 3.1-109. URL: http://cran.rproject.org/web/packages/nlme/index.html

Redmond, L., and P. L. Mokhtarian. 2001. The positive utility of the commute: Modeling ideal commute time and relative desired commute amount. Transportation 28(2): 179-205. http://dx.doi.org/10.1023/A:1010366321778

Rietveld, P., and S. van Woudenberg. 2003. The utility of traveling when destinations are heterogeneous. How much better is the next destination as one travels further? Journal of Geographical Systems, 5(2): 207-222. http://dx.doi.org/10.1007/s10109-003-0098-8

Schwanen, T. 2002. Urban form and commuting behavior: A cross-European perspective. Tijdschrift voor Economische en Sociale Geografie 93(3): 336-343. http://dx.doi.org/10.1111/1467-9663.00206 
Schwanen, T., F. M. Dieleman, and M. Dijst. 2001. Travel behavior in Dutch monocentric and polycentric urban systems. Journal of Transport Geography 9(3): 173-186. http://dx.doi.org/10.1016/S0966-6923(01)00009-6

Schwanen, T., M. Dijst, and F. M. Dieleman. 2004. Policies for urban form and their impact on travel: The Netherlands experience. Urban Studies 41(3): 579-603. http://dx.doi.org/10.1080/0042098042000178690

Scott, M. 1985. The San Francisco Bay Area. A Metropolis in Perspective. Berkeley, CA: University of California Press.

Song, Y., B. Popkin, and P. Gordon-Larsen. 2013. A national-level analysis of neighborhood form metrics. Landscape and Urban Planning 116: 73-85. http://dx.doi.org/10.1016/j.landurbplan.2013.04.002

Stead, D. 2001. Relationships between land use, socioeconomic factors, and travel patterns in Britain. Environment and Planning B: Planning and Design 28(4): 499-528. http://dx.doi.org/10.1068/b2677

Sun, X., C. Wilmot, and T. Kasturi. 1998. Household travel, household characteristics, and land use an empirical study from the 1994 Portland Activity-Based Travel Survey. Transportation Research Record 1617: 10-17. http://dx.doi.org/10.3141/1617-02

Turcotte, M. 2006. Like commuting? Workers' perceptions of their daily commute. Canadian Social Trends 82: 35-40. URL: http://www2.canada.com/vancouversun/news/extras/commuting.pdf

Van Wee, B. 2002. Land use and transport: Research and policy challenges. Journal of Transport Geography 10(4): 259-271. http://dx.doi.org/10.1016/S0966-6923(02)00041-8

Walker, R. 2001. Industry builds the city: The suburbanization of manufacturing in the San Francisco Bay Area, 1850-1940. Journal of Historical Geography 27(1): 36-57. http://dx.doi.org/10.1006/jhge.2000.0268

Walker, R. 2007. The Country in the City: The Greening of the San Francisco Bay Area. Seattle, WA: University of Washington Press.

Washington, S. P., M. G. Karlaftis, and F. L. Mannering. 2011. Statistical and econometric methods for transportation data analysis. Boca Raton, FL: Chapman and Hall/CRC.

West, B., K. B. Welch, and A. T. Galecki. 2007. Linear Mixed Models: A Practical Guide Using Statistical Software. Boca Raton, FL: Chapman and Hall/CRC.

Young, W. and J. Morris. 1981. Evaluation by individuals of their travel time to work. Transportation Research Record 794: 51-59. URL: http://trid.trb.org/view.aspx?id=172650

Zegras, C. 2010. The built environment and motor vehicle ownership and use: Evidence from Santiago de Chile. Urban Studies 47(8): 1793-1817. http://dx.doi.org/10.1177/0042098009356125

Zhang, M. 2004. The role of land use in travel mode choice: Evidence from Boston and Hong Kong. Journal of the American Planning Association 70(3): 344-360. http://dx.doi.org/10.1080/01944360408976383

Zhang, M., and N. Kukadia. 2005. Metrics of urban form and the modifiable areal unit problem metrics of urban form. Transportation Research Record 1902: 71-79. http://dx.doi.org/10.3141/1902-09 